\title{
A meta-analysis of potential biomarkers associated with severity of coronavirus disease 2019 (COVID-19)
}

Celestin Danwang ${ }^{1 *}$ D , Francky Teddy Endomba ${ }^{2,3}$, Jan René Nkeck ${ }^{4}$ Dominic Leandry Angong Wouna ${ }^{5}$, Annie Robert ${ }^{1}$ and Jean Jacques Noubiap ${ }^{6}$

\begin{abstract}
Background: Prognostic factors for the Coronavirus disease 2019 (COVID1-9) are not well established. This study aimed to summarize the available data on the association between the severity of COVID-19 and common hematological, inflammatory and biochemical parameters.

Methods: EMBASE, MEDLINE, Web of sciences were searched to identify all published studies providing relevant data. Random-effects meta-analysis was used to pool effect sizes.

Results: The bibliographic search yielded 287 citations, 31 of which were finally retained. Meta-analysis of standardized mean difference (SMD) between severe and non-severe COVID-19 cases showed that CK-MB (SMD = 0.68,95\%Cl: 0.48;0.87; P-value:<0.001), troponin I (SMD =0.71, 95\%Cl:0.42;1.00; P-value:<0.001), D-dimer (SMD = 0.54, 95\%Cl:0.31;0.77; $P$-value: $<0.001)$, prothrombin time $(S M D=0.48,95 \% C l: 0.23 ; 0.73 ; P$-value: $<0.001)$, procalcitonin $(S M D=0.72,95 \% C l: 0.34 ; 1,11 ; P$-value: $<0.001)$, interleukin-6 (SMD = 0.93, 95\%Cl: 0.25;1.61;P-value: 0.007),C-reactive protein (CRP) (SMD = 1.34, 95\%Cl:0.83;1.86; P-value:<0.001), ALAT (SMD =0.53, 95\%Cl: 0.34;0,71; $P$-value:<0.001), ASAT ( $S M D=0.96,95 \% C l: 0.58 ; 1.34 ; P$-value: $<0.001), \mathrm{LDH}(\mathrm{SMD}=1.36,95 \% \mathrm{Cl}: 0.75 ; 1.98 ; P$-value: $<0.001), \mathrm{CK}(\mathrm{SMD}=0.48$, 95\%Cl: 0.10;0.87; P-value:0.01), total bilirubin (SMD =0.32, 95\%Cl: 0.18;0.47;P-value: $<0.001), \gamma$-GT (SMD = 1.03, 95\%Cl: $0.83 ; 1.22 ; P$-value: $<0.001)$, myoglobin $(\mathrm{SMD}=1.14,95 \% \mathrm{Cl}$ : 0.81;1.47; $P$-value: $<0.001)$, blood urea nitrogen $(\mathrm{SMD}=$ $0.32,95 \% \mathrm{Cl}$ : 0.18;0.47;P-value:<0.001) and Creatininemia ( $\mathrm{SMD}=0.18,95 \% \mathrm{Cl}: 0.01 ; 0.35 ; P$-value:0.04) were significantly more elevated in severe cases, in opposition to lymphocyte count (SMD $=-0.57,95 \% \mathrm{Cl}:-0.71 ;-0.42 ; P$-value: $<0.001$ ) and proportion of lymphocytes (SMD $=-0.81,95 \% \mathrm{Cl}:-1.12 ;-0.49 ;$-value: $<0.001)$ which were found to be significantly lower in severe patients with other biomarker such as thrombocytes $(\mathrm{SMD}=-0.26,95 \% \mathrm{Cl}$ : -0.48 ; -0.04 ; P-value:0.02), eosinophils (SMD $=-0.28,95 \% \mathrm{Cl}:-0.50 ;-0.06 ; P$-value:0.01), haemoglobin (SMD $=-0.20,95 \% \mathrm{Cl}:-0.37$,0.03; $P$-value:0.02), albuminemia (SMD-1.67,95\%Cl -2.40; - 0.94; $P$-value:<0.001), which were also lower. Furthermore, severe COVID-19 cases had a higher risk to have lymphopenia ( $R R=1.66,95 \% \mathrm{Cl}: 1.26 ; 2.20 ; P$-value:0.002), thrombocytopenia (RR=1.86,95\%Cl: 1.59;2.17; P-value: <0.001), elevated procalcitonin level $(\mathrm{RR}=2.94,95 \% \mathrm{Cl}: 2.09-$ 4.15; P-value:< 0.001), CRP (RR =1.41,95\%Cl: 1.17-1.70; P-value:0.003), ASAT(RR =2.27, 95\%Cl: 1.76;2.94; P-value:<0.001), $\mathrm{CK}(\mathrm{RR}=2.61,95 \% \mathrm{Cl}: 1.35 ; 5.05 ;$;-value: 0.01), Creatininemia (RR $=3.66,95 \% \mathrm{Cl}: 1.53 ; 8.81 ; P$-value: 0.02$)$ and LDH blood level (RR $=2.03,95 \% \mathrm{Cl}: 1.42 ; 290 ;$ P-value: 0.003).
\end{abstract}

(Continued on next page)

\footnotetext{
* Correspondence: danram07@yahoo.fr

${ }^{1}$ Epidemiology and Biostatistics Unit, Institut de Recherche Expérimentale et Clinique, Université catholique de Louvain, Brussels, Belgium

Full list of author information is available at the end of the article
}

(c) The Author(s). 2020 Open Access This article is licensed under a Creative Commons Attribution 4.0 International License, which permits use, sharing, adaptation, distribution and reproduction in any medium or format, as long as you give appropriate credit to the original author(s) and the source, provide a link to the Creative Commons licence, and indicate if changes were made. The images or other third party material in this article are included in the article's Creative Commons licence, unless indicated otherwise in a credit line to the material. If material is not included in the article's Creative Commons licence and your intended use is not permitted by statutory regulation or exceeds the permitted use, you will need to obtain permission directly from the copyright holder. To view a copy of this licence, visit http://creativecommons.org/licenses/by/4.0/ The Creative Commons Public Domain Dedication waiver (http://creativecommons.org/publicdomain/zero/1.0/) applies to the data made available in this article, unless otherwise stated in a credit line to the data. 
(Continued from previous page)

Conclusion: Some inflammatory (procalcitonin, CRP), haematologic (lymphocyte, Thrombocytes), and biochemical (CK-MB, Troponin I, D-dimer, ASAT, ALAT, LDH, Y-GT) biomarkers are significantly associated with severe COVID-19. These biomarkers might help in prognostic risk stratification of patients with COVID-19.

Keywords: Prognostic biomarkers, COVID-19, Meta-analysis

\section{Introduction}

Coronavirus disease 2019 (COVID-19) which emerged in Wuhan, China, has spread to almost all countries and regions of the world, becoming one of the most lethal pandemic after the Spanish flu in 1918-1920. It is caused by an RNA virus (2019 novel coronavirus or 2019-nCoV or SARS-CoV-2). As of July 13, 2020, a total of 12,768,307 confirmed COVID-19 cases and 566,654 related deaths have been reported [1]. Beyond its important morbidity and mortality and the huge burden of health care systems, COVID-19 has a massive societal and economic impact globally.

To date, there is no established curative treatment for COVID-19. Although some drugs such as hydroxychloroquine are integrated in treatment guidelines or under investigation in interventional studies, the management of COVID-19 is mostly supportive. [2-4] Identifying biological abnormalities induced by COVID-19 may contribute to a better understanding of the pathophysiology of the disease and ultimately guide the development of targeted adjuvant therapies besides antivirals drugs. Furthermore, such information on the biological profile of COVID-19 can guide clinicians in the assessment and treatment of these patients.

Clinically, most of COVID-19 cases (80\%) are either asymptomatic or have mild forms. [4, 5] However, about 13.8 and $6.1 \%$ have severe and critical life-threatening disease that require admission to hospital and sometimes in the intensive care unit. [5] In the context of outstretched heath care systems and limited resources, risk stratification is pivotal to identify patients who the most need in-hospital and intensive management. Biomarkers along with some clinical factors might help to predict adverse outcomes among COVID-19 patients. Hence, we conducted this systematic review and meta-analysis to summarize available data on the association between some common hematological, inflammatory, biochemical parameters and the severity of COVID-19.

\section{Methods}

This review is reported according to the MOOSE (Metaanalysis Of Observational Studies in Epidemiology) guidelines [6].

\section{Search strategy and selection criteria}

We searched PubMed, EMBASE and Web of sciences from inception to April 18, 2020, to identify studies in
English or French reporting biological work-up results in patients with biologically confirmed (with polymerase chain reaction assays) COVID-19. The search strategies are presented in the appendix (Supplementary Table 1 and 2). Furthermore, the reference list of eligible studies was analysed to identify potential additional data sources. For duplicates publications or studies conducted on the same group of patients, the study with the largest sample size was considered. We excluded studies from which we could not obtain data on the prevalence of abnormalities or the mean and standard deviation (or median and interquartile range) of the reported biomarker in severe and non-severe patients.

\section{Data extraction and management}

Two investigators (CD and FTE) independently assessed the articles retrieved from the literature search to determine their potential eligibility based on titles and abstracts. The full texts of selected articles were then downloaded and assessed for final inclusion. Discrepancies were resolved by discussion and consensus.

An electronic data abstraction form was used by four investigators (CD, FTE, JRN and DLAW) to extracted relevant information in accordance with the objectives of the review. One investigator (JJN) crosscheck extracted data. For each study data extracted included: surname of the first author, year of publication, country and city where the study was conducted, study design, timing of data collection, sample size, proportion of males, study sample size, biological abnormalities reported, mean and standard deviation (or median and interquartile range) of reported biomarkers.

All patients presenting blood oxygen saturation $\leq 93 \%$; respiratory failure; septic shock; multiple organ dysfunction; dyspnea;respiratory rate greater than $30 / \mathrm{min}, \mathrm{PaO} 2 /$ $\mathrm{FiO} 2$ ratio $<300$, and/or lung infiltrates $>50 \%$ of the lung field within $24-48 \mathrm{~h}$ were considered as severe cases as recommended by the World Health Organization. [5]

\section{Data synthesis and analysis}

A DerSimonian and Laird random-effects meta-analysis model was used to obtain the pooled effect size within the statistical software $\mathrm{R}$ (version 3.6.2). For studies reporting median and interquartile range of the biomarker, only those with a reported number of cases greater than 25 were included in the standardized mean 
difference (SMD) meta-analysis. Prior to pooling effect sizes, the standard deviation of each mean value was computed from the interquartile range by taking the difference between Q3 and Q1 and dividing by 1.35 as recommended in the Cochrane handbook of systematic review [7]. Pooled OR and SMD of each biomarker are reported with their $95 \%$ confidence intervals.

Cochran's $X^{2}$ and the $I^{2}$ tests were used respectively to assess the presence and the amount of heterogeneity, with the cut-off of $\mathrm{I}^{2}$ values of 25,50 and $75 \%$ representing low, medium and high heterogeneity respectively $[8$, 9]. Publication bias was assess by the inspection of the Funnel plot and the Egger test $(p<0.10)$ [10]. Unless otherwise specify, a $p$ value $<0.05$ was considered as statistically significant for all analysis.

\section{Results}

\section{Characteristics of included studies}

The bibliographical search yielded 287 eligible articles, of which 31 were finally retained for the systematic review, and 16 for the meta-analysis as depicted in the study selection process (Supplementary Figure 1). Two studies were conducted in Singapore [11, 12] and all the others in China in 2020 [13-41] (Table 1). Twelve of the included studies were conducted in Wuhan. Twentyeight studies had collected data retrospectively while three were prospective. All included studies except one (which was cross sectional) were case series with patients having a mean age ranging from 9 to 70.5 years in severe cases and from 7.5 to 59.7 years in non-severe cases. The proportion of males ranged from between 40.7 and $73 \%$. Three studies reported data on survivors and non-survivors (Table 1).

\section{Full blood count abnormalities}

Severe COVID-19 cases had significantly lower lymphocyte count (SMD $=-0.57,95 \% \mathrm{CI}:-0.71 ;-0.42 ;$ P-value $:<$ $0.001 ; n=3337$ ), proportion of lymphocytes (SMD = 0.81, 95\%CI: $-1.12 ;-0.49 ; \quad P$-value $:<0.001 ; n=1974)$, thrombocytes $(\mathrm{SMD}=-0.26,95 \% \mathrm{CI}:-0.48 ;-0.04 ; P$ value: $0.02 ; n=2064)$, eosinophils $(\mathrm{SMD}=-0.28,95 \% \mathrm{CI}$ :$0.50 ;-0.06 ;$ P-value: $0.01 ; n=436$ ) and haemoglobin $(\mathrm{SMD}=-0.20,95 \% \mathrm{CI}:-0.37,-0.03 ;$ P-value $0.02 ; n=843)$. They had a significantly higher neutrophil count (SMD = 0.52, 95\%CI: $0.28 ; 0.76 ; \quad P$-value: $<0.001 ; \quad n=2156$ ) (Table 2). Moreover, non-survivor cases of COVID-19 had a significantly lower level of lymphocytes $(\mathrm{SMD}=$ $0.67,95 \%$ CI: $-1.18 ;-0.17$; P-value: $0.009 ; n=327$ ) and higher level of white blood cells $(\mathrm{SMD}=0.89,95 \% \mathrm{CI}$ : 0.04; 1.75 ; P-value: $0.04 ; n=275$ ) (Table 3 ).

Furthermore, cases of severe COVID-19 were more likely to present lymphopenia ( $\mathrm{RR}=1.66,95 \% \mathrm{CI}$ : 1.26 ; 2.20; P-value:0.002; $n=1636$ ), and thrombocytopenia $(\mathrm{RR}=1.86,95 \% \mathrm{CI}: 1.59 ; 2.17 ;$ P-value $:<0.001 ; n=1226)$ but not leukopenia $(\mathrm{RR}=0.93,95 \% \mathrm{CI}$ : 0.46;1.86; P-value: $0.81 ; n=1684$ ) (Table 4). More details on the metaanalysis and forest plots are available in the appendix (Supplementary file).

\section{Blood clotting abnormalities}

There was a significant difference in D-dimer and prothrombin time (PT) between severe and non-severe cases, with severe cases having a higher D-dimer level $(\mathrm{SMD}=0.54,95 \% \mathrm{CI}: 0.31 ; 0.77 ;$ P-value $:<0.001 ; n=1583)$ and prothrombin time $(\mathrm{SMD}=0.48,95 \% \mathrm{CI}: 0.23 ; 0.73 ; P$ value: $<0.001 ; n=357)$.

\section{Increased cardiac injury biomarkers in severe cases}

Troponin I blood level were significantly higher in severe patients $(\mathrm{SMD}=0.71,95 \% \mathrm{CI}: 0.42 ; 1.00 ;$ P-value $: 0.001$; $n=430)$ as well as CK-MB levels (SMD $=0.68,95 \%$ CI: $0.48 ; 0.87 ;$ P-value $:<0.001 ; n=1150$ ), and this was consistent across all studies included in the meta-analysis of the above-mentioned biomarkers (Table 2).

\section{Inflammation}

Severe COVID-19 cases had significantly higher blood level of procalcitonin $(\mathrm{SMD}=0.72,95 \% \mathrm{CI}$ : $0.34 ; 1,11 ; P$ value: $<0.001 ; n=1509)$, interleukin-6 $(\mathrm{SMD}=0.93$, 95\%CI: $0.25 ; 1.61 ;$ P-value: $0.007 ; n=875$ ), and C-reactive protein $(\mathrm{SMD}=1.34,95 \% \mathrm{CI}: 0.83 ; 1.86 ;$ P-value: $<0.001$; $n=1974$ ) (Table 2). Moreover, IL-6 was significantly higher in non-survivor compare to survivor cases $(\mathrm{SMD}=1.23,95 \% \mathrm{CI}$ : 0.77;1.68; $P$-value $:<0.001 ; n=275)$.

Severe cases were more likely to have a higher procalcitonin level $(\mathrm{RR}=2.94,95 \% \mathrm{CI}$ : 2.09; 4.15; P-value: < $0.001 ; n=1262)$, and CRP (RR $=1.41,95 \% \mathrm{CI}: 1.17 ; 1.70$; P-value: $0.003 ; n=1349)$ (Table 4).

\section{Biochemical abnormalities}

Overall, severe COVID-19 cases were found to have higher level of ALAT (SMD = 0.53, 95\%CI: 0.34;0,71; $P$ value: $<0.001 ; n=2292)$ and ASAT (SMD $=0.96,95 \% \mathrm{CI}$ : 0.58;1.34; P-value: $<0.001 ; n=2103)$, LDH $(\mathrm{SMD}=1.36$, 95\%CI: 0.75;1.98; P-value: $<0.001 ; n=1660)$, CK (SMD = 0.48, 95\%CI: 0.10;0.87; P-value:0.01; $\mathrm{n}=1660)$, total bilirubin $(\mathrm{SMD}=0.32,95 \% \mathrm{CI}$ : 0.18;0.47; P-value: $<0.001$; $n=1597), \gamma$-GT $(\mathrm{SMD}=1.03,95 \% \mathrm{CI}: 0.83 ; 1.22 ; P$-value: $<0.001 ; n=616)$, myoglobin (SMD $=1.14,95 \%$ CI: 0.81 ; 1.47; P-value: $<0.001 ; n=1012$ ) and blood urea nitrogen $(\mathrm{SMD}=0.32,95 \% \mathrm{CI}: 0.18 ; 0.47 ;$ P-value $: 0.001 ; n=1197)$ and Creatininemia $(\mathrm{SMD}=0.18,95 \% \mathrm{CI}: 0.01 ; 0.35 ; \quad P$ value: $0.04 ; n=1785$ ). Albuminemia was found to be lower in severe cases (SMD-1.67,95\%CI -2.40; - 0.94; $P$ value: $<0.001 ; n=1040$ ) (Table 2).

Severe COVID-19 cases were more likely to have higher blood level of ASAT(RR $=2.27,95 \% \mathrm{CI}$ : 1.76;2.94; P-value: $<0.001 ; n=1538), \mathrm{CK}(\mathrm{RR}=2.61,95 \% \mathrm{CI}: 1.35$; 


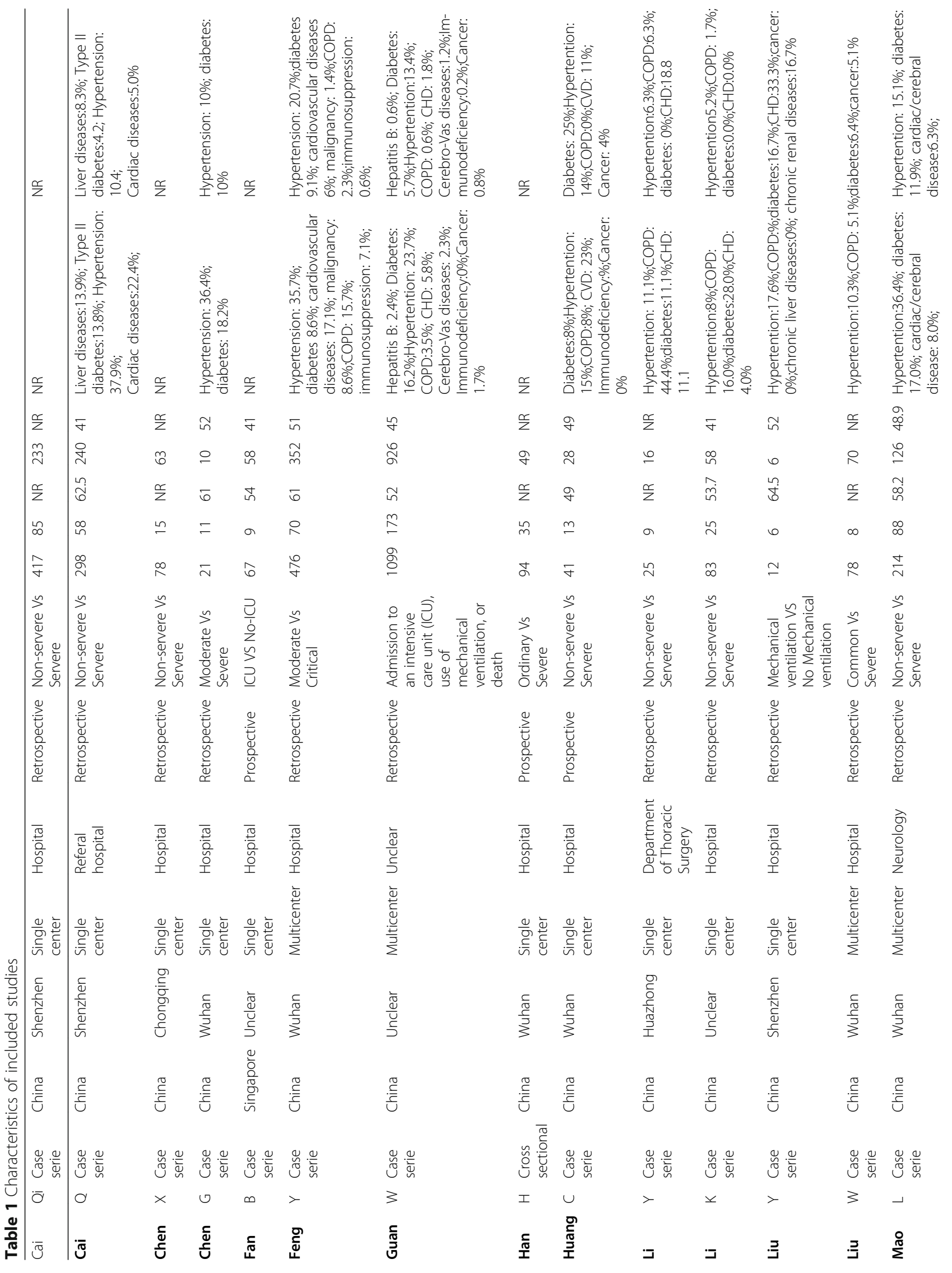




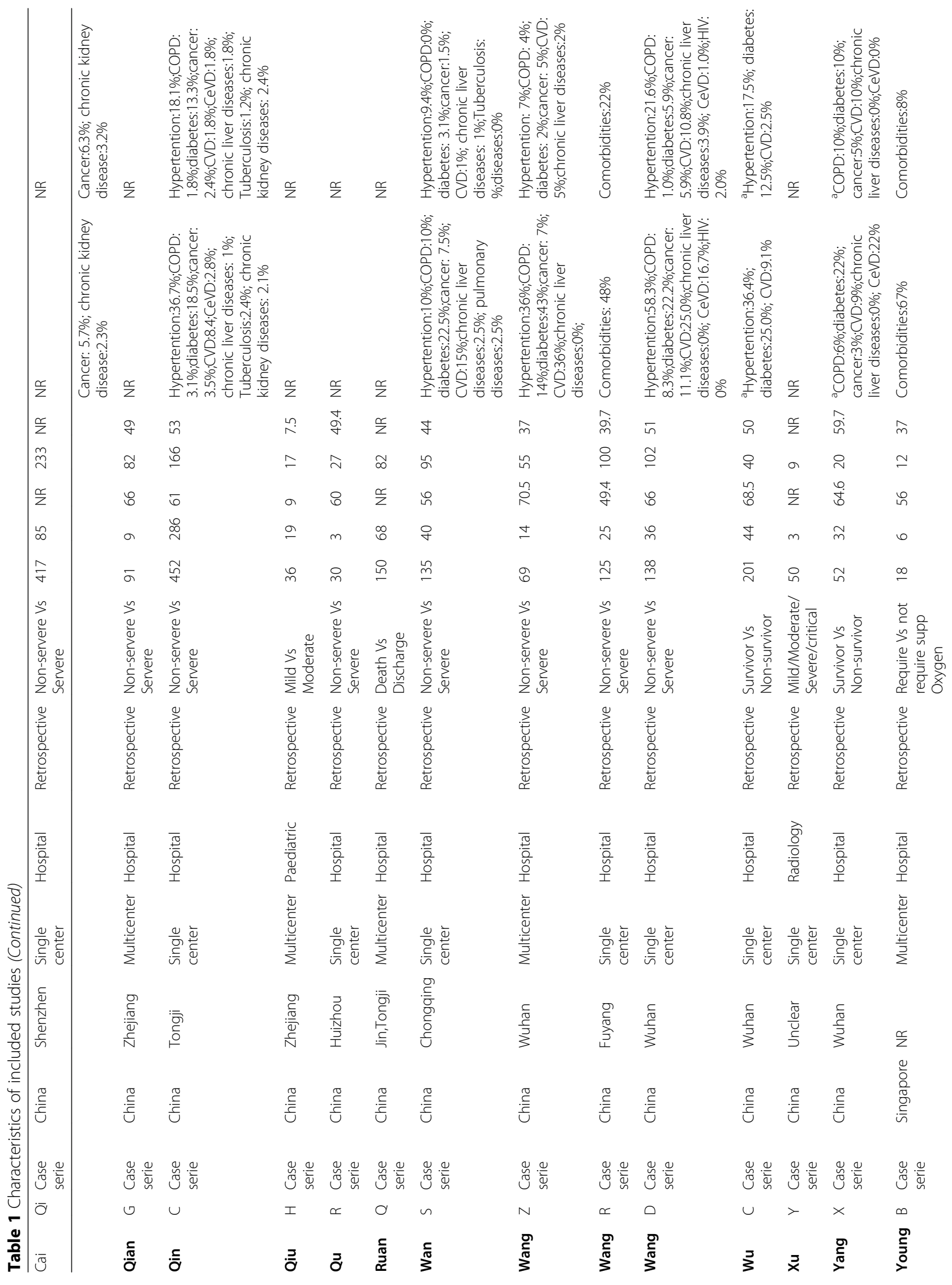




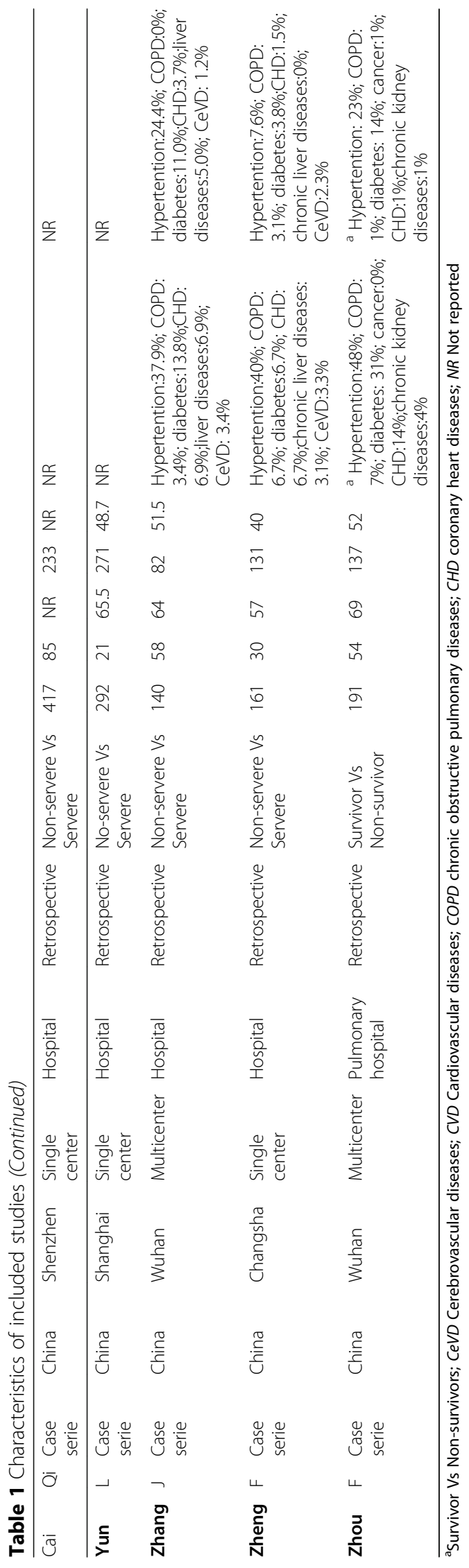


Table 2 Summary results of the meta-analysis of mean values of each Biomarker in severe vs non-severe cases

\begin{tabular}{|c|c|c|c|c|c|c|}
\hline Anomalies & SMD (95\% Cl) & P-value & $\begin{array}{l}\text { Heterogeneity } \\
12(\%)\end{array}$ & Number of studies & Sample size for severe & Sample size for Non-severe \\
\hline \multicolumn{7}{|l|}{ Inflammation } \\
\hline Procalcitonin & $0.72(0.34 ; 1,11)$ & $<0.001$ & 87 & 6 & 467 & 1042 \\
\hline CRP & $1.34(0.83 ; 1.86)$ & $<0.001$ & 95 & 9 & 670 & 1304 \\
\hline IL-6 & $0.93(0.25 ; 1.61)$ & 0.007 & 93 & 3 & 369 & 506 \\
\hline ESR & $0.27(-0.16 ; 0.70)$ & 0.22 & 90 & 4 & 435 & 1029 \\
\hline \multicolumn{7}{|l|}{ Blood routine } \\
\hline Lymphocytes count & $-0.57(-0.71 ;-0.42)$ & $<0.001$ & 61 & 12 & 888 & 2449 \\
\hline Lymphocytes \% & $-0.81(-1.12 ;-0.49)$ & $<0.001$ & 62 & 3 & 367 & 306 \\
\hline Thrombocytes & $-0.26(-0.48 ;-0.04)$ & 0.02 & 72 & 7 & 445 & 1619 \\
\hline Eosinophils & $-0.28(-0.50 ;-0.06)$ & 0.01 & 0 & 2 & 114 & 322 \\
\hline Neutrophils & $0.52(0.28 ; 0.76)$ & $<0.001$ & 80 & 9 & 646 & 1510 \\
\hline Haemoglobin & $-0.20(-0.37 ;-0.03)$ & 0.02 & 0 & 4 & 165 & 678 \\
\hline Monocytes & $-0.09(-0.27 ; 0.08)$ & 0.30 & 14 & 4 & 372 & 426 \\
\hline White Blood Cells & $0.13(-0.14 ; 0.39)$ & 0.35 & 90 & 11 & 1133 & 2566 \\
\hline $\mathrm{CD} 3+\mathrm{T}$ & $-0.77(-0.95 ;-0.59)$ & $<0.001$ & 0 & 2 & 307 & 437 \\
\hline \multicolumn{7}{|l|}{ Cardiac injury biomarkers } \\
\hline CK-MB & $0.68(0.48 ; 0.87)$ & $<0.001$ & 30 & 4 & 185 & 965 \\
\hline Troponin I & $0.71(0.42 ; 1.00)$ & $<0.001$ & 0 & 2 & 57 & 373 \\
\hline \multicolumn{7}{|l|}{ Biochemestry } \\
\hline CK & $0.48(0.10 ; 0.87)$ & 0.01 & 89 & 7 & 343 & 1317 \\
\hline Myoglobin & $1.14(0.81 ; 1.47)$ & $<0.001$ & 66 & 3 & 149 & 863 \\
\hline ALAT & $0.53(0.34 ; 0,71)$ & $<0.001$ & 68 & 10 & 507 & 1785 \\
\hline ASAT & $0.96(0.58 ; 1.34)$ & $<0.001$ & 91 & 9 & 453 & 1650 \\
\hline Albumin & $-1.67(-2.40 ;-0.94)$ & $<0.001$ & 93 & 4 & 185 & 855 \\
\hline Creatinemia & $0.18(0.01 ; 0.35)$ & 0.04 & 49 & 8 & 368 & 1417 \\
\hline Blood urea nitrogen & $0.58(0.23 ; 0.93)$ & 0.001 & 83 & 5 & 277 & 920 \\
\hline Total bilirubin & $0.32(0.18 ; 0.47)$ & $<0.001$ & 28 & 7 & 344 & 1253 \\
\hline LDH & $1.36(0.75 ; 1.98)$ & $<0.001$ & 95 & 7 & 343 & 1317 \\
\hline Potassium & $-0.10(-0.43 ; 0.23)$ & 0.55 & 79 & 3 & 248 & 1061 \\
\hline Sodium & $-0.19(-0.72 ; 0.34)$ & 0.49 & 91 & 3 & 231 & 983 \\
\hline$\gamma$-GT & $1.03(0.83 ; 1.22)$ & $<0.001$ & 0 & 2 & 143 & 473 \\
\hline \multicolumn{7}{|l|}{ Blood clothing } \\
\hline PT & $0.48(0.23 ; 0.73)$ & $<0.001$ & 16 & 3 & 111 & 246 \\
\hline D-dimer & $0.54(0.31 ; 0.77)$ & $<0.001$ & 69 & 7 & 348 & 1235 \\
\hline aPT & $0.17(-0.23 ; 0.57)$ & 0.40 & 74 & 4 & 164 & 274 \\
\hline Fibrinogen & $0.09(-0.56 ; 0.74)$ & 0.78 & 77 & 2 & 56 & 320 \\
\hline
\end{tabular}

SMD Standardized mean difference; CRP C-reactive protein; CK Creatine kinase; IL-6 interleukin-6; ALAT alanine amino-transferase;

ASAT aspartate amino-transferase; $L D H$ Lactate dehydrogenese; PT prothrombin time; aPT activated partial thromboplastin;

5.05; P-value: $0.01 ; n=1086)$, Creatininemia ( $\mathrm{RR}=3.66$, 95\%CI: $1.53 ; 8.81 ;$ P-value: $0.02 ; n=1084)$, LDH (RR = 2.03, 95\%CI: 1.42;2.90; P-value: $0.003 ; n=1138$ ) (Table 4).

Concerning non-survivors, total bilirubin (SMD $=0.55$, 95\%CI: $0.20 ; 0.89 ;$ P-value: $0.002 ; n=136)$ and $\mathrm{LDH}$ (SMD $=1.48,95 \% \mathrm{CI}: \quad 0.57 ; 2.40 ;$ P-value $: 0.002 ; n=268$ ) were significantly higher in non-survivors compare to survivors (Table 3).

\section{Discussion}

This review shows that patients with a severe form of COVID-19 have higher level of CK-MB,troponin I, D- dimer, prothrombin time, procalcitonin, interleukin-6, C-reactive protein, ALAT, ASAT, LDH, CK, total bilirubin, $\gamma-G T$, myoglobin, blood urea nitrogen, creatininemia and lower level of lymphocyte, thrombocytes, eosinophils, haemoglobin and albuminemia.

\section{Inflammation and COVID-19}

It has been shown that COVID-19 infection is associated with a severe systemic immune response drive by a "cytokine storm". [42-44] Our data point to an association between procalcitonin (PCT), CRP levels and the severity of the disease. This is supported by previous findings which has reported elevated levels of several pro 
Table 3 Summary results of the meta-analysis of mean values of each Biomarker in non-survivor and survivor cases

\begin{tabular}{|c|c|c|c|c|c|c|}
\hline Anomalies & SMD $(95 \% \mathrm{Cl})$ & P-value & $\begin{array}{l}\text { Heterogeneity } \\
\text { I2 (\%) }\end{array}$ & Number of studies & Sample size for Non-survivor & Sample size survivor \\
\hline \multicolumn{7}{|l|}{ Inflammation } \\
\hline IL-6 & $1.23(0.77 ; 1.68)$ & $<0.001$ & 61 & 2 & 98 & 177 \\
\hline \multicolumn{7}{|l|}{ Blood routine } \\
\hline Lymphocytes count & $-0.67(-1.18 ;-0.17)$ & 0.009 & 75 & 3 & 130 & 197 \\
\hline White Blood Cells & $0.89(0.04 ; 1.75)$ & 0.04 & 90 & 2 & 98 & 177 \\
\hline \multicolumn{7}{|l|}{ Biochemestry } \\
\hline Creatinemia & $-0.09(-0.46 ; 0.27)$ & 0.62 & 12 & 2 & 76 & 60 \\
\hline Total bilirubin & $0.55(0.20 ; 0.89)$ & 0.002 & 0 & 2 & 76 & 60 \\
\hline LDH & $1.48(0.57 ; 2.40)$ & 0.002 & 90 & 2 & 98 & 170 \\
\hline Ferritin & $0.76(-0.33 ; 1.90)$ & 0.18 & 93 & 2 & 90 & 122 \\
\hline \multicolumn{7}{|l|}{ Blood clothing } \\
\hline PT & $0.30(-0.14 ; 0.75)$ & 0.18 & 68 & 3 & 130 & 188 \\
\hline
\end{tabular}

SMD Standardized mean difference; IL-6 interleukin-6; $L D H$ Lactate dehydrogenese; PT prothrombin time; CD3+ TCD3+ positif T lymphocytes

inflammatory cytokines including IL-2, IL-6, IL-7, MCP1, and TNF alpha, which contributes to increase classical inflammatory biomarkers such as PCT and CRP and are found to be higher in the severe forms of the disease. [42, 43, 45] Mechanistically, it has been show that, after the virus entry in the pneumocytes via the ACE2 receptor, it triggers a systemic inflammatory response, creating an immune dysfunction with a hyperactivity of $\mathrm{T}$ lymphocytes and the release of pro inflammatory cytokines mentioned above. [42, 43, 46] If the inflammation is initially protective, it appears secondarily that most cellular and tissue lesions are more the result of hyperinflammation than of the direct effect of the virus. [42, 43] These two phenomena may favor at the respiratory level, pulmonary lesions, by hypercapillary permeability and pulmonary edema, leading to acute respiratory distress. [42, 47] Hyperinflammation at the systemic level may lead to vascular, thrombotic and cytokines' toxicity phenomena, resulting in multisystemic lesions. [43, 44, 48] Moore et al. showed that, these severe, multi-organ damage may worsen the prognosis despite supportive therapies. [49]

Table 4 Summary results of the meta-analysis of odd ratio of each Biomarker in severe vs non-severe cases

\begin{tabular}{|c|c|c|c|c|c|c|}
\hline Anomalies & $\mathrm{RR}(95 \% \mathrm{Cl})$ & P-value & $\begin{array}{l}\text { Heterogeneity } \\
12(\%)\end{array}$ & Number of studies & Sample size for severe & Sample size for non-severe \\
\hline \multicolumn{7}{|l|}{ Inflammation } \\
\hline Eleveted procalcitonin & $2.94(2.09 ; 4.15)$ & $<0.001$ & 32 & 9 & 321 & 941 \\
\hline Eleveted CRP & $1.41(1.17 ; 1.70)$ & 0.003 & 0 & 8 & 328 & 1021 \\
\hline \multicolumn{7}{|l|}{ Blood routine } \\
\hline Lymphopenia & $1.66(1.26 ; 2.20)$ & 0.002 & 30 & 11 & 411 & 1225 \\
\hline Leucopenia & $0.93(0.46 ; 1.86)$ & 0.81 & 83 & 10 & 384 & 1300 \\
\hline Thrombocytopenia & $1.86(1.59 ; 2.17)$ & $<0.001$ & 0 & 5 & 250 & 976 \\
\hline Thrombocytosis & $0.88(0.26 ; 2.95)$ & & 0 & 2 & 53 & 122 \\
\hline \multicolumn{7}{|l|}{ Biochemestry } \\
\hline Eleveted LDH & $2.03(1.42 ; 2.90)$ & 0.003 & 57 & 7 & 239 & 899 \\
\hline Eleveted ASAT & $2.27(1.76 ; 2.94)$ & $<0.001$ & 26 & 8 & 354 & 1184 \\
\hline Eleveted ALAT & $160(1.34 ; 1.90)$ & 0.002 & 60 & 5 & 283 & 1042 \\
\hline Eleveted CK & $2.61(1.35 ; 5.05)$ & 0.01 & 37 & 6 & 248 & 841 \\
\hline Eleveted Creatininemia & $3.66(1.53 ; 8.81)$ & 0.02 & 0 & 4 & 227 & 857 \\
\hline Eleveted total bilirubin & $1.42(0.18 ; 11.26)$ & 0.28 & 0 & 2 & 158 & 725 \\
\hline \multicolumn{7}{|l|}{ Blood clothing } \\
\hline D-dimer & $1.50(0.89 ; 2.56)$ & 0.08 & 0 & 3 & 156 & 510 \\
\hline
\end{tabular}

OR odd ratio; CRP C-reactive protein; CK Creatine kinase; IL-6 interleukin-6; ALAT alanine amino-transferase; $A S A T$ aspartate amino-transferase; $L D H$ Lactate dehydrogenese 
Thus for clinicians, the measurement of classical and accessible inflammatory markers namely PCT and CRP, may help assessing the hyper inflammatory activity, and thus the severity of cases of severe infections. Furthermore, the use of therapies targeting inflammation to reduce the deleterious effects of the cytokine storm appear to be necessary. In this line, some studies have reported the beneficial effects of immunosuppressive and immunomodulatory therapies. [50-52] However, the benefit of the use of corticosteroids and non-steroidal anti-inflammatory drugs to reduce hyperinflammation during the $2019-\mathrm{nCoV}$ infection is still controversial. [39-41]

\section{Cardiac biomarkers imbalanced and COVID-19}

Our analysis revealed that severe COVID-19 cases have elevated levels of biomarkers of cardiomyocytes injury such as Troponin I, CK-MB, CK and myoglobin. Numerous previous researches have reported a cardiac involvement in patients with 2019-nCoV. [53-56] In a recently published study, Lippi and colleagues reported that the values of cardiac Troponin I were significantly increased in COVID-19 cases with severe disease than in those without. [55] Notwithstanding the incomplete knowledge on its pathophysiology, the mainly suggested mechanisms are: myocardial ischemia due to increased oxygen demand but in the context of hypoxemia and plaque disruption triggered by cytokine storm; these two being most frequently encountered among patients with coronary artery disease. [57-60] Also, myocardial inflammation, which can be the result of systemic immune response is another mechanism of heart injury among COVID-19 cases. [61, 62] Likewise, it has been hypothesised a direct viral toxicity through the interaction with ACE2 receptors highly expressed by some pericytes. [59] A thorough cardiac assessment should therefore be conducted in the follow-up of severe COVID-19 cases and manage properly to avoid adverse outcome.

\section{Lymphopenia and other full blood count imbalance in severe COVID-19 cases}

Hematological changes encountered in the course of the novel coronavirus infection are common and concern mainly white blood cells and platelets. [63] In our study, some keys parameters modifications, notably lymphopenia and thrombocytopenia, are associated with severe form of the disease. [64]

Indeed, we found decreased overall mean levels of lymphocyte count among severe 2019-nCoV patients. Moreover, patients with severe 2019-nCoV infection were more likely to have lymphopenia. Low lymphocyte count has also been reported for other viral respiratory infection such as the one due to Respiratory Syncytial Virus (RSV). [65] This immune response marked by a profound lymphopenia seem to be is delay complication that come after an early massive release of cytokine during the course of the SRAS-Cov-2 lung injury. [66-68] The effects of COVID-19 on lymphocytes can be explained by direct and/or indirect mechanisms. The direct insult could be related to 2019-nCoV cytotoxicity, sustained by active viral replication within pool of infected lymphocytes. [67, 69] However, angiotensin-converting enzyme 2 (ACE2) has been identified as a functional cellular receptor for the COVID-19, a protein that is not expressed on circulating $\mathrm{B}$ or $\mathrm{T}$ lymphocytes. $[66,70]$ Studies suggested a potential role of alveolar macrophages which can promote viral entry via antigen presentation to $\mathrm{T}$ lymphocytes. $[66,67]$ Indirect lymphocytes damage could appear through huge cytokines release which can induce cells apoptosis. [66, 68, 69] In addition, high glucocorticoids levels induced by severe 2019-nCov can pertain to the down regulation of proinflammatory lymphokine ultimately lead to the lymphocyte activation and proliferation alteration . [67, 68]. [71] Clinicians should therefore keep in mind that severe cases of COVID-19 have depressed lymphocyte levels and are therefore more prone to infection.

Another key hematological disturbance found in our review was thrombocytopenia. Indeed, our analysis revealed significantly reduced mean platelets count in cases with severe COVID-19. Moreover, patients with severe form of the disease were more likely to have low platelets counts. Some potential mechanisms of SRASassociated thrombocytopenia have been proposed. Coronavirus can infect bone marrow cells and thereby reduce platelet production. [72] Indeed some strains of coronavirus like $\mathrm{HCoV}-229$ have their receptor on humans cells like those of kidney, lung and platelets, named Human amino peptidase N (CD13). [73] 2019$\mathrm{nCoV}$ infection may also increase peripheral destruction of platelet $[72,74]$ by immunological mechanism by generating auto antibodies and immune complex. [75] Similar response have been reported for other viruses like HIV 1 in which Anti-platelet membrane GPIIIa49-66 IgG antibodies can cross-react with the HIV-1GP 160/ 120 antigen. [75] Other pathways can be the consumption of platelet following severe lung inflammation result in platelets activation and formation of microthrombi. [72] Thrombocytopenia, which makes cases with severe forms of the disease susceptible to primary coagulation impairment, is therefore an important element to consider and address in the daily management and evaluation of these patients.

\section{COVID-19 and blood coagulation}

Four main coagulation biomarkers disturbances were found in severe COVID-19 cases namely higher serum $\mathrm{D}$-dimers, longer prothrombin time (PT), and lower 
platelets counts. Moreover, we found that patients with severe 2019-nCoV infection are more likely to have increase serum D-dimers.

Coronavirus disease 2019 can affect haemostasis and blood coagulation in many ways, both regarding abnormal bleeding risk and thromboembolism. [72, 76-79] In addition to thrombocytopenia mechanistic hypotheses stated earlier, it must be suggest the potential implication of COVID-19 liver injury an aetiological element of haemostasis disorder though the impaired production of coagulation factors. [72, 76, 77]

Concerning D-dimers, increased levels might be the result of the sepsis-induced disseminated intravascular coagulation and reflect thromboembolic risk in severe COVID-19 cases. [80-82] There are mounting evidences supporting the key pathological role of thromboembolic processes in SARS-CoV-2 disease and severity. [83-86] Due to the low specificity of this biomarker, its results in Covid-19 patients should be interpreted in the context of other associated conditions that may also potentially increase D-dimer levels.

Decreased platelet counts and increased prothrombin time in patients with covid-19 are probably due to consumption coagulopathy. The latter occurs as a result of an abnormal increase in the activation of procoagulant pathways which induces a decrease in plasma concentrations of fibrinogen, platelets and other clotting factors. [87] A daily assessment of the coagulation profile of cases with severe forms of the disease appears vital and the correction of those abnormalities unavoidable to improve the prognosis. Cases of COVID-19 with bloodclotting abnormalities should be managed very closely and invasive treatments that may lead to bleeding should be avoided.

\section{Biochemical abnormalities in severe COVID-19 cases}

Numerous liver biomarkers abnormalities have been described as being associated with COVID-19 encompassing increased levels of total bilirubin, transaminases, $\gamma$ GT, LDH, and low albumin levels. [88-91] Our results revealed that some of these biomarkers (ASAT/ALAT, $\gamma$-GT, LDH) have a significantly higher level in severe cases, and that severe cases are more likely to have high levels of ASAT and LDH.

It has been reported a virus-induced cytopathic effect notably through the binding with the ACE2 receptor for its target cells entry. $[91,92]$ Another potential triggering factor of detrimental liver consequences is immunemediated inflammation in parallel with the "cytokine storm". [76, 93, 94] Moreover, the immune responses ensured by $B$ and $T$ cells lymphocytes can also sustain this inflammation. $[67,68]$ It has also been put forward stress on sepsis related ischemic/hypoxic liver injury as putative mechanisms of abnormal hepatic function. [95,
96] Hepatic sinuses congestion related to thrombosis and/or high levels of positive end expiratory pressure can also be a contributing explanatory mechanisms of liver damage. [93, 95, 97] Likewise, COVID-19 patients may experience drug-induced liver injury (DILI), [93, 98] and reactivation of pre-existing hepatic conditions (going from viral hepatitis to liver cirrhosis). [90, 97, 99] Therefore, drugs which are known to be hepatotoxic or which are metabolized by the liver should be administered with caution or should be avoided in severe cases. Nevertheless, the results of liver biomarkers in COVID19 cases must be interpreted in the context of the presence of other comorbidities that may induce an increase in these biomarkers.

Our findings point to an overall higher levels of urea nitrogen and creatinine among COVID-19 severe cases. Further studies are needed to better understand renal involvement in severe COVID-19 cases, especially since some pathophysiological hypotheses suggest the possibility of kidney damages related to COVID-19 infection. [100-103]

The current research provides evidence-based elements that can help clinicians in decision making when dealing with COVID-19 cases. Future studies should explore novel biomarkers, such as non-coding RNAs or proteomics, for disease progression and severity of COVID-19 and similar diseases in order to build powerful prediction tools.

The results of the current review should be interpreted in the context of some limitations. Firstly, it was not possible to assess the dynamic of biomarkers and to determine whether the samples were taken on admission or later during hospitalization. Therefore, the kinetic of biomarkers during the disease progression to severity cannot be established. Secondly, all the studies included in the meta-analysis were from China. Different biological patterns might be observed across populations from various geographical and ethnic background. Therefore, this limits the generalizability of our findings and call to more research on the topic in population from different countries and ethnicities. Thirdly, the measurement of biomarkers was probably different between studies, with various devices and diagnostic reference values. However, in most studies, there was low to moderate heterogeneity, suggesting that observations were consistent across studies. Nevertheless, this study is one of the first to analyse potential biomarkers associated with the severity of 2019-nCoV infection. We used state-of-the-art statistical methods in order to derive the most accurate estimates.

\section{Conclusion}

Some inflammatory (procalcitonin, CRP), haematologic (lymphocyte, Thrombocytes), and biochemical (CK-MB, 
Troponin I, D-dimer, ASAT, ALAT, LDH, $\gamma$-GT) biomarkers are significantly associated with severe COVID19. These biomarkers might help in prognostic risk stratification of patients with COVID-19. Our findings could also contribute in the establishment of an accurate and reproducible COVID-19 biological severity score.

\section{Supplementary information}

Supplementary information accompanies this paper at https://doi.org/10. 1186/s40364-020-00217-0.

Additional file 1 Supplementary Table 1. Search strategy in PubMed. Supplementary Table 2. Search strategy in EMBASE. Supplementary Figure 1. The review process.

\section{Acknowledgments}

None.

\section{Authors' contributions}

$C D, F T E$ and JJN conceived the idea of the study. CD did the literature search. CD and FTE selected the studies. CD, FTE, JRN and DLAW extracted the relevant information. CD and JJN synthesized the data, CD wrote the first draft of the paper with FTE, JRN and DLAW. CD, FTE, JRN, DLAW, AR and JJN critically revised successive drafts of the paper and approved the final version. CD and JJN are the guarantor of the review.

\section{Funding}

None.

Availability of data and materials

All related materials are available in the appendix.

Ethics approval and consent to participate

Not applicable.

\section{Consent for publication}

All authors approved the final version of the manuscript and agree for publication.

\section{Competing interests}

We declare no competing interests.

\section{Author details \\ ${ }^{1}$ Epidemiology and Biostatistics Unit, Institut de Recherche Expérimentale et Clinique, Université catholique de Louvain, Brussels, Belgium. ${ }^{2}$ Psychiatry Internship Program, University of Bourgogne, 21000 Dijon, France. ${ }^{3}$ Health Economics \& Policy Research and Evaluation for Development Results Group, Yaoundé, Cameroon. ${ }^{4}$ Department of Internal medicine, Faculty of Medicine and Biomedical Sciences, University of Yaoundé I, Yaoundé, Cameroon. ${ }^{5}$ General medical practices unit, Bertoua Regional Hospital, Bertoua, Cameroon. ${ }^{6}$ Centre for Heart Rhythm Disorders, University of Adelaide and Royal Adelaide Hospital, Adelaide, Australia.}

Received: 4 June 2020 Accepted: 20 August 2020

Published online: 31 August 2020

\section{References}

1. Coronavirus disease (COVID-19) - World Health Organization [Internet]. [cited 2020 Jul 14]. Available from: https://www.who.int/emergencies/ diseases/novel-coronavirus-2019.

2. Zhou M, Qi J, Li X, Zhang Z, Yao Y, Wu D, et al. The proportion of patients with thrombocytopenia in three human-susceptible coronavirus infections: a systematic review and meta-analysis. Br J Haematol. 2020;13.

3. Cascella M, Rajnik M, Cuomo A, Dulebohn SC, Di Napoli R. Features, Evaluation and Treatment Coronavirus (COVID-19). In: StatPearls. Treasure Island: StatPearls Publishing; 2020. [cited 2020 Apr 21]. Available from: http://www.ncbi.nlm.nih.gov/books/NBK554776/.
4. Gandhi RT, Lynch JB, del Rio C. Mild or Moderate Covid-19. N Engl J Med. 2020;0(0) null.

5. Report of the WHO-China Joint Mission on Coronavirus Disease 2019 (COVID-19) [Internet]. [cited 2020 Apr 30]. Available from: https://www.who. int/publications-detail/report-of-the-who-china-joint-mission-on-coronavirusdisease-2019-(covid-19).

6. Stroup DF, Berlin JA, Morton SC, Olkin I, Williamson GD, Rennie D, et al. Meta-analysis of observational studies in epidemiology: a proposal for reporting. Meta-analysis of observational studies in epidemiology (MOOSE) group. JAMA. 2000 Apr 19;283(15):2008-12.

7. Higgins J, Thomas J, Chandler J, Cumpston M, Li T, Page M, et al. Cochrane Handbook for Systematic Reviews of Interventions [Internet]. [cited 2020 Apr 30]. Available from: www.training.cochrane.org/handbook.

8. Huedo-Medina TB, Sánchez-Meca J, Marín-Martínez F, Botella J. Assessing heterogeneity in meta-analysis: Q statistic or 12 index? Psychol Methods. 2006 Jun;11(2):193-206.

9. Cochran WG. The combination of estimates from different experiments. Biometrics. 1954;10(1):101-29.

10. Egger M, Davey Smith G, Schneider M, Minder C. Bias in meta-analysis detected by a simple, graphical test. BMJ. 1997;315(7109):629-34.

11. Fan BE, Chong VCL, Chan SSW, Lim GH, Lim KGE, Tan GB, et al. Hematologic parameters in patients with COVID-19 infection. Am J Hematol. [cited 2020 Apr 21];n/a(n/a). Available from: https://onlinelibrary.wiley.com/doi/abs/10.1 002/ajh.25774

12. Young $B E$, Ong SWX, Kalimuddin S, Low JG, Tan SY, Loh J, et al. Epidemiologic features and clinical course of patients infected with SARSCoV-2 in Singapore. JAMA. 2020;323(15):1488-94.

13. Cai $Q$, Huang D, Yu H, Zhu Z, Xia Z, Su Y, et al. Characteristics of liver tests in COVID-19 patients. J Hepatol. 2020;13.

14. Cai Q, Huang D, Ou P, Yu H, Zhu Z, Xia Z, et al. COVID-19 in a designated infectious diseases hospital outside Hubei Province, China. Allergy. 2020;

15. Mao L, Jin H, Wang M, Hu Y, Chen S, He Q, et al. Neurologic Manifestations of Hospitalized Patients With Coronavirus Disease 2019 in Wuhan, China. JAMA Neurol. 2020; [cited 2020 Apr 30]; Available from: https:// jamanetwork.com/journals/jamaneurology/fullarticle/2764549.

16. Wang $R$, Pan M, Zhang $X$, Fan X, Han M, Zhao F, et al. Epidemiological and clinical features of 125 hospitalized patients with COVID-19 in Fuyang, Anhui, China. Int J Infect Dis IJID Off Publ Int Soc Infect Dis. 2020.

17. Feng Y, Ling Y, Bai T, Xie Y, Huang J, Li J, et al. COVID-19 with different severity: a multi-center study of clinical features. Am J Respir Crit Care Med. 2020 Apr;10.

18. Wan S, Xiang Y, Fang W, Zheng Y, Li B, Hu Y, et al. Clinical features and treatment of COVID-19 patients in Northeast Chongqing. J Med Virol. 2020;21.

19. Wang Z, Yang B, Li Q, Wen L, Zhang R. Clinical features of 69 cases with coronavirus disease 2019 in Wuhan, China. Clin Infect Dis Off Publ Infect Dis Soc Am. 2020.

20. Xu Y-H, Dong J-H, An W-M, Lv X-Y, Yin X-P, Zhang J-Z, et al. Clinical and computed tomographic imaging features of novel coronavirus pneumonia caused by SARS-CoV-2. J Inf Secur. 2020;80(4):394-400.

21. Chen $X$, Yang $Y$, Huang $M$, Liu L, Zhang $X$, Xu J, et al. Differences between COVID-19 and suspected then confirmed SARS-CoV-2-negative pneumonia: a retrospective study from a single center. J Med Virol. 2020;1.

22. Li Y-K, Peng S, Li L-Q, Wang Q, Ping W, Zhang N, et al. Clinical and transmission characteristics of Covid-19 - a retrospective study of 25 cases from a single thoracic surgery department. Curr Med Sci. 2020 Apr;40(2):295-300.

23. Chen G, Wu D, Guo W, Cao Y, Huang D, Wang H, et al. Clinical and immunological features of severe and moderate coronavirus disease 2019. J Clin Invest. 2020 May 1;130(5):2620-9.

24. Li K, Wu J, Wu F, Guo D, Chen L, Fang Z, et al. The clinical and chest CT features associated with severe and critical COVID-19 pneumonia. Investig Radiol. 2020;29.

25. Huang $C$, Wang $Y$, Li X, Ren L, Zhao J, Hu Y, et al. Clinical features of patients infected with 2019 novel coronavirus in Wuhan, China. Lancet. 2020;395(10223):497-506

26. Zheng F, Tang W, Li H, Huang Y-X, Xie Y-L, Zhou Z-G. Clinical characteristics of 161 cases of corona virus disease 2019 (COVID-19) in Changsha. Eur Rev Med Pharmacol Sci. 2020;24(6):3404-10.

27. Qiu H, Wu J, Hong L, Luo Y, Song Q, Chen D. Clinical and epidemiological features of 36 children with coronavirus disease 2019 (COVID-19) in Zhejiang, China: an observational cohort study. Lancet Infect Dis. 2020;0(0) [cited 2020 May 1]. Available from: https://www.thelancet.com/journals/ laninf/article/PIIS1473-3099(20)30198-5/abstract. 
28. Zhou F, Yu T, Du R, Fan G, Liu Y, Liu Z, et al. Clinical course and risk factors for mortality of adult inpatients with COVID-19 in Wuhan, China: a retrospective cohort study. Lancet. 2020 Mar 28;395(10229):1054-62.

29. Guan W, Ni Z, Hu Y, Liang W, Ou C, He J, et al. Clinical characteristics of coronavirus disease 2019 in China. N Engl J Med. 2020 Apr 30;382(18):1708-20.

30. Zhang J-J, Dong X, Cao Y-Y, Yuan Y-D, Yang Y-B, Yan Y-Q, et al. Clinical characteristics of 140 patients infected with SARS-CoV-2 in Wuhan, China. Allergy. 2020.

31. Wang D, Hu B, Hu C, Zhu F, Liu X, Zhang J, et al. Clinical characteristics of 138 hospitalized patients with 2019 novel coronavirus-infected pneumonia in Wuhan, China. JAMA. 2020;323(11):1061-9.

32. Han H, Yang L, Liu R, Liu F, Wu K-L, Li J, et al. Prominent changes in blood coagulation of patients with SARS-CoV-2 infection. Clin Chem Lab Med. 2020 Mar;16.

33. Wu C, Chen X, Cai Y, Xia J, Zhou X, Xu S, et al. Risk Factors Associated With Acute Respiratory Distress Syndrome and Death in Patients With Coronavirus Disease 2019 Pneumonia in Wuhan, China. JAMA Intern Med. 2020; [cited 2020 Apr 30]; Available from: https://jamanetwork.com/journals/ jamainternalmedicine/fullarticle/2763184.

34. Liu Y, Yang Y, Zhang C, Huang F, Wang F, Yuan J, et al. Clinical and biochemical indexes from 2019-nCoV infected patients linked to viral loads and lung injury. Sci China Life Sci. 2020;63(3):364-74.

35. Liu W, Tao Z-W, Wang L, Yuan M-L, Liu K, Zhou L, et al. Analysis of factors associated with disease outcomes in hospitalized patients with 2019 novel coronavirus disease. Chin Med J (Engl). 2020; [cited 2020 May 4]; Available from: https://www.ncbi.nlm.nih.gov/pmc/articles/PMC7147279/.

36. Qin C, Zhou L, Hu Z, Zhang S, Yang S, Tao Y, et al. Dysregulation of immune response in patients with COVID-19 in Wuhan, China. Clin Infect Dis Off Publ Infect Dis Soc Am. 2020.

37. Ruan Q, Yang K, Wang W, Jiang L, Song J. Clinical predictors of mortality due to COVID-19 based on an analysis of data of 150 patients from Wuhan, China. Intensive Care Med. 2020.

38. Qu R, Ling Y, Zhang Y-H-Z, Wei L-Y, Chen X, Li X-M, et al. Platelet-tolymphocyte ratio is associated with prognosis in patients with coronavirus disease-19. J Med Virol. 2020;17.

39. Qian G-Q, Yang N-B, Ding F, Ma AHY, Wang Z-Y, Shen Y-F, et al. Epidemiologic and Clinical Characteristics of 91 Hospitalized Patients with COVID-19 in Zhejiang, China: A retrospective, multi-centre case series. QJM Int J Med. 2020; [cited 2020 May 2]; Available from: https://www.ncbi.n/m. nih.gov/pmc/articles/PMC7184349/.

40. Yang X, Yu Y, Xu J, Shu H, Xia J, Liu H, et al. Clinical course and outcomes of critically ill patients with SARS-CoV-2 pneumonia in Wuhan, China: a singlecentered, retrospective, observational study. Lancet Respir Med. 2020;0(0) [cited 2020 May 2]. Available from: https://www.thelancet.com/journals/ lanres/article/PIIS2213-2600(20)30079-5/abstract.

41. Clinical analysis on risk factors for COVID-19 patients becoming severe patients [Internet]. MyBioGate Global COVID-19 Resources Platform. 2020 [cited 2020 May 4]. Available from: https://events.mybiogate.com/covid19ru/clinicalanalysis-on-risk-factors-for-covid-19-patients-becoming-severe-patients/.

42. Jin Y, Yang H, Ji W, Wu W, Chen S, Zhang W, et al. Virology, epidemiology, pathogenesis, and control of COVID-19. Viruses. 2020;12(4).

43. Rothan HA, Byrareddy SN. The epidemiology and pathogenesis of coronavirus disease (COVID-19) outbreak. J Autoimmun. 2020 May;109:102433.

44. Tay MZ, Poh CM, Rénia L, MacAry PA, Ng LFP. The trinity of COVID-19: immunity, inflammation and intervention. Nat Rev Immunol. 2020;28:1-12.

45. Cao X. COVID-19: immunopathology and its implications for therapy. Nat Rev Immunol. 2020;9:1-2.

46. Yuki K, Fujiogi M, Koutsogiannaki S. COVID-19 pathophysiology: A review. Clin Immunol Orlando Fla. 2020 Apr 20; Available from: https://www.ncbi. nlm.nih.gov/pmc/articles/PMC7169933/.

47. Sarzi-Puttini P, Giorgi V, Sirotti S, Marotto D, Ardizzone S, Rizzardini G, et al. COVID-19, cytokines and immunosuppression: what can we learn from severe acute respiratory syndrome? Clin Exp Rheumatol. 2020 Apr; 38(2):337-42.

48. Mehta P, McAuley DF, Brown M, Sanchez E, Tattersall RS, Manson JJ, et al. COVID-19: consider cytokine storm syndromes and immunosuppression. Lancet Lond Engl. 2020;395(10229):1033-4.

49. Moore BJB, June $\mathrm{CH}$. Cytokine release syndrome in severe COVID-19. Science. 2020;17.

50. Zhao M. Cytokine storm and immunomodulatory therapy in COVID-19: role of chloroquine and anti-IL-6 monoclonal antibodies. Int J Antimicrob Agents. 2020; Available from: https://www.ncbi.nlm.nih.gov/pmc/articles/PMC7161506/.
51. Zhang C, Wu Z, Li J-W, Zhao H, Wang G-Q. The cytokine release syndrome (CRS) of severe COVID-19 and Interleukin-6 receptor (IL-6R) antagonist Tocilizumab may be the key to reduce the mortality. Int J Antimicrob Agents. 2020;29:105954.

52. Mehta B, Luo Y, Xu J, Sammaritano L, Salmon J, Lockshin M, et al. Trends in maternal and fetal outcomes among pregnant women with systemic lupus erythematosus in the United States. Ann Intern Med. 2019;171(3):164-71.

53. Aghagoli G, Gallo Marin B, Soliman LB, Sellke FW. Cardiac involvement in COVID-19 patients: risk factors, predictors, and complications: a review. J Card Surg. 2020;19.

54. Inciardi RM, Lupi L, Zaccone G, Italia L, Raffo M, Tomasoni D, et al. Cardiac involvement in a patient with coronavirus disease 2019 (COVID-19). JAMA Cardiol. 2020;27.

55. Lippi G, Lavie CJ, Sanchis-Gomar F. Cardiac troponin I in patients with coronavirus disease 2019 (COVID-19): evidence from a meta-analysis. Prog Cardiovasc Dis. 2020;10.

56. Shi S, Qin M, Shen B, Cai Y, Liu T, Yang F, et al. Association of cardiac injury with mortality in hospitalized patients with COVID-19 in Wuhan, China. JAMA Cardiol. 2020.

57. Akhmerov A, Marban E. COVID-19 and the heart. Circ Res. 2020;7.

58. Atri D, Siddiqi HK, Lang J, Nauffal V, Morrow DA, Bohula EA. COVID-19 for the cardiologist: a current review of the virology, Clinical Epidemiology, Cardiac and Other Clinical Manifestations and Potential Therapeutic Strategies. JACC Basic Transl Sci. 2020.

59. Chen L, Li X, Chen M, Feng Y, Xiong C. The ACE2 expression in human heart indicates new potential mechanism of heart injury among patients infected with SARS-CoV-2. Cardiovasc Res. 2020 May 1;116(6):1097-100.

60. Zheng $Y-Y, M a ~ Y-T$, Zhang J-Y, Xie X. COVID-19 and the cardiovascular system. Nat Rev Cardiol. 2020;17(5):259-60.

61. Zeng J-H, Liu Y-X, Yuan J, Wang F-X, Wu W-B, Li J-X, et al. First case of COVID-19 complicated with fulminant myocarditis: a case report and insights. Infection. 2020;10:1-5.

62. Ammirati E, Wang DW. SARS-CoV-2 inflames the heart. The importance of awareness of myocardial injury in COVID-19 patients. Int J Cardiol. 2020; [cited 2020 May 2]; Available from: https://www.ncbi.nlm.nih.gov/pmc/ articles/PMC7134214/.

63. Fan BE, Chong VCL, Chan SSW, Lim GH, Lim KGE, Tan GB, et al. Hematologic parameters in patients with COVID-19 infection. Am J Hematol. [cited 2020 May 1];n/a(n/a). Available from: https://onlinelibrary.wiley.com/doi/abs/10.1 002/ajh.25774

64. Chng WJ, Lai HC, Earnest A, Kuperan P. Haematological parameters in severe acute respiratory syndrome. Clin Lab Haematol. 2005 Feb;27(1):15-20.

65. Leroy EM, Baize S, Debre P, Lansoud-Soukate J, Mavoungou E. Early immune responses accompanying human asymptomatic Ebola infections. Clin Exp Immunol. 2001 Jun;124(3):453-60.

66. Li H, Liu L, Zhang D, Xu J, Dai H, Tang N, et al. SARS-CoV-2 and viral sepsis: observations and hypotheses. Lancet. 2020;0(0) [cited 2020 May 1]. Available from: https://www.thelancet.com/journals/lancet/article/PIIS0140-6736(20)3 0920-X/abstract.

67. Li G, Fan Y, Lai Y, Han T, Li Z, Zhou P, et al. Coronavirus infections and immune responses. J Med Virol. 2020;92(4):424-32.

68. Shi Y, Wang Y, Shao C, Huang J, Gan J, Huang X, et al. COVID-19 infection: the perspectives on immune responses. Cell Death Differ. 2020;23:1-4.

69. Terpos E, Ntanasis-Stathopoulos I, Elalamy I, Kastritis E, Sergentanis TN, Politou M, et al. Hematological findings and complications of COVID-19. Am J Hematol. [cited 2020 May 1];n/a(n/a). Available from: https://onlinelibrary. wiley.com/doi/abs/10.1002/ajh.25829.

70. Hamming I, Timens W, Bulthuis MLC, Lely AT, Navis GJ, van Goor H. Tissue distribution of ACE2 protein, the functional receptor for SARS coronavirus. A first step in understanding SARS pathogenesis. J Pathol. 2004 Jun;203(2): $631-7$.

71. Panesar NS, Lam CWK, Chan MHM, Wong CK, Sung JJY. Lymphopenia and neutrophilia in SARS are related to the prevailing serum cortisol. Eur J Clin Investig. 2004 May;34(5):382-4.

72. Xu P, Zhou Q, Xu J. Mechanism of thrombocytopenia in COVID-19 patients. Ann Hematol. 2020;15:1-4.

73. Yeager CL, Ashmun RA, Williams RK, Cardellichio CB, Shapiro LH, Look AT, et al. Human aminopeptidase $\mathrm{N}$ is a receptor for human coronavirus $229 \mathrm{E}$ Nature. 1992 Jun 4;357(6377):420-2.

74. Qu R, Ling Y, Zhang Y, Wei L, Chen X, Li X, et al. Platelet-to-lymphocyte ratio is associated with prognosis in patients with coronavirus disease-19. J 
Med Virol. [cited 2020 May 1];n/a(n/a). Available from: https://onlinelibrary. wiley.com/doi/abs/10.1002/jmv.25767.

75. Nardi M, Tomlinson S, Greco MA, Karpatkin S. Complement-independent, peroxide-induced antibody lysis of platelets in HIV-1-related immune thrombocytopenia. Cell. 2001 Sep 7;106(5):551-61.

76. Zhang C, Shi L, Wang F-S. Liver injury in COVID-19: management and challenges. Lancet Gastroenterol Hepatol. 2020;5(5):428-30.

77. Bikdeli B, Madhavan MV, Jimenez D, Chuich T, Dreyfus I, Driggin E, et al. COVID-19 and thrombotic or thromboembolic disease: implications for prevention, antithrombotic therapy, and follow-up. J Am Coll Cardiol. 2020; 15.

78. Xiong $M$, Liang $X$, Wei Y-D. Changes in blood coagulation in patients with severe coronavirus disease 2019 (COVID-19): a meta-analysis. Br J Haematol. 2020;18.

79. Jose RJ, Manuel A. COVID-19 cytokine storm: the interplay between inflammation and coagulation. Lancet Respir Med. 2020;27.

80. Giannis D, Ziogas IA, Gianni P. Coagulation disorders in coronavirus infected patients: COVID-19, SARS-CoV-1, MERS-CoV and lessons from the past. J Clin Virol Off Publ Pan Am Soc Clin Virol. 2020;127:104362.

81. Lillicrap D. Disseminated intravascular coagulation in patients with 2019nCoV pneumonia. J Thromb Haemost JTH. 2020;18(4):786-7.

82. Tang N, Li D, Wang X, Sun Z. Abnormal coagulation parameters are associated with poor prognosis in patients with novel coronavirus pneumonia. J Thromb Haemost JTH. 2020;18(4):844-7.

83. Kollias A, Kyriakoulis KG, Dimakakos E, Poulakou G, Stergiou GS, Syrigos K. Thromboembolic risk and anticoagulant therapy in COVID-19 patients: emerging evidence and call for action. Br J Haematol. 2020;18.

84. Klok FA, Kruip MJHA, van der Meer NJM, Arbous MS, Gommers DAMPJ, Kant KM, et al. Incidence of thrombotic complications in critically ill ICU patients with COVID-19. Thromb Res. 2020;10.

85. Xu Z, Shi L, Wang Y, Zhang J, Huang L, Zhang C, et al. Pathological findings of COVID-19 associated with acute respiratory distress syndrome. Lancet Respir Med. 2020;8(4):420-2.

86. Yao XH, Li TY, He ZC, Ping YF, Liu HW, Yu SC, et al. A pathological report of three COVID-19 cases by minimally invasive autopsies. Zhonghua Bing Li Xue Za Zhi. 2020;49(0):E009.

87. Consumption Coagulopathy: Practice essentials, Pathophysiology, Epidemiology. 2020 [cited 2020 Jul 15]; Available from: https://emedicine. medscape.com/article/955059-overview.

88. Feng G, Zheng KI, Yan Q-Q, Rios RS, Targher G, Byrne CD, et al. COVID-19 and liver dysfunction: current insights and emergent therapeutic strategies. J Clin Transl Hepatol. 2020;8(1):18-24.

89. Cai Q, Huang D, Yu H, Zhu Z, Xia Z, Su Y, et al. COVID-19: Abnormal liver function tests. J Hepatol. 2020; [cited 2020 May 1]; Available from: http:// www.sciencedirect.com/science/article/pii/S016882782030218X.

90. Sun J, Aghemo A, Forner A, Valenti L. COVID-19 and liver disease. Liver Int Off J Int Assoc Study Liver. 2020;6.

91. Guiwen $G$, Lin $G$, Jianwen W, Xiajie W, Tianhao M, Siwen P, et al. Exploring the mechanism of liver enzyme abnormalities in patients with novel coronavirus-infected pneumonia. Chin J Hepatol. 2020;28(02):E002.

92. Hoffmann M, Kleine-Weber H, Krüger N, Müller M, Drosten C, Pöhlmann S. The novel coronavirus 2019 (2019-nCoV) uses the SARS-coronavirus receptor ACE2 and the cellular protease TMPRSS2 for entry into target cells. bioRxiv. 2020; 2020.01.31.929042.

93. Musa S. Hepatic and gastrointestinal involvement in coronavirus disease 2019 (COVID-19): what do we know till now? Arab J Gastroenterol Off Publ Pan-Arab Assoc Gastroenterol. 2020;21(1):3-8.

94. Ward SE, Loutfy MR, Blatt LM, Siminovitch KA, Chen J, Hinek A, et al. Dynamic changes in clinical features and cytokine/chemokine responses in SARS patients treated with interferon alfacon-1 plus corticosteroids. Antivir Ther. 2005;10(2):263-75.

95. Fan Z, Chen L, Li J, Cheng X, Null JY, Tian C, et al. Clinical Features of COVID-19-Related Liver Damage. Clin Gastroenterol Hepatol Off Clin Pract J Am Gastroenterol Assoc. 2020.

96. Strnad P, Tacke F, Koch A, Trautwein C. Liver - guardian, modifier and target of sepsis. Nat Rev Gastroenterol Hepatol. 2017 Jan;14(1):55-66.

97. Li J, Fan J-G. Characteristics and mechanism of liver injury in 2019 coronavirus disease. J Clin Transl Hepatol. 2020 Mar 28;8(1):13-7.

98. Boeckmans J, Rodrigues RM, Demuyser T, Piérard D, Vanhaecke T, Rogiers V. COVID-19 and drug-induced liver injury: a problem of plenty or a petty point? Arch Toxicol. 2020;8:1-3.
99. Mao R, Liang J, Shen J, Ghosh S, Zhu L-R, Yang H, et al. Implications of COVID-19 for patients with pre-existing digestive diseases. Lancet Gastroenterol Hepatol. 2020;5(5):426-8.

100. Ronco C, Reis T. Kidney involvement in COVID-19 and rationale for extracorporeal therapies. Nat Rev Nephrol. 2020;9:1-3.

101. Diao B, Wang C, Wang R, Feng Z, Tan Y, Wang H, et al. Human Kidney is a Target for Novel Severe Acute Respiratory Syndrome Coronavirus 2 (SARSCoV-2) Infection. medRxiv. 2020; 2020.03.04.20031120.

102. Malha L, Mueller FB, Pecker MS, Mann SJ, August P, Feig PU. COVID-19 and the Renin-Angiotensin System. Kidney Int Rep. 2020; [cited 2020 May 1]; Available from: https://www.ncbi.nlm.nih.gov/pmc/articles/PMC7118533/.

103. Cheng $Y$, Luo $R$, Wang $K$, Zhang $M$, Wang Z, Dong $L$, et al. Kidney disease is associated with in-hospital death of patients with COVID-19. Kidney Int. 2020;97(5):829-38

\section{Publisher's Note}

Springer Nature remains neutral with regard to jurisdictional claims in published maps and institutional affiliations.
Ready to submit your research? Choose BMC and benefit from:

- fast, convenient online submission

- thorough peer review by experienced researchers in your field

- rapid publication on acceptance

- support for research data, including large and complex data types

- gold Open Access which fosters wider collaboration and increased citations

- maximum visibility for your research: over $100 \mathrm{M}$ website views per year

At BMC, research is always in progress.

Learn more biomedcentral.com/submissions 